\title{
Adaptabilidade e estabilidade e a produtividade de grãos em cultivares de feijão preto recomendadas no Brasil nas últimas cinco décadas
}

\author{
Adaptability and stability and grain yield of black common \\ bean cultivars used in Brazil in the last five decades
Leiri Daiane Barili ${ }^{I}$ Naine Martins do Vale ${ }^{I}$ Rodolfo de Castro Amaral ${ }^{\text {II }}$
José Eustáquio de Souza Carneiro ${ }^{\mathrm{III}}$ Fabyano Fonseca e Silva ${ }^{\mathrm{IV}}$ \\ Pedro Crescêncio Souza Carneirov
}

RESUMO

O objetivo deste trabalho foi estudar os parâmetros de adaptabilidade e estabilidade fenotípica e avaliar o incremento na produtividade de grãos em genótipos de feijão preto, desenvolvidos pelos programas brasileiros de melhoramento genético entre os anos de 1960 a 2013. Os experimentos foram realizados considerando 38 cultivares e duas linhagens em quatro ambientes (Coimbra e Viçosa nas safras da seca e de inverno de 2013), usando um delineamento em blocos casualizados com três repetições. Os resultados evidenciaram incremento efetivo na produtividade de grãos, proporcionado pela recomendação de novas cultivares pelos programas de melhoramento de feijão do Brasil nas últimas cinco décadas. Além disso, a análise da interação GxA indicou que as cultivares recomendadas após o ano de 2005 foram as que apresentaram conjuntamente altas produtividades de grãos, ampla adaptabilidade e alta previsibilidade de comportamento.

Palavras-chave: Phaseolus vulgaris L., melhoramento genético, interação $G x A$, incremento na produtividade.

\section{ABSTRACT}

The objective of this research was to study the parameters of adaptability and phenotypic stability and estimate the increase in grain yield in black common bean genotypes developed by brazilian breeding programs between the years 1960-2013. The experiments were carried out considering 38 cultivars and two lines in four different environments (Coimbra and Viçosa cities, and dry and winter seasons of 2013 year) by using a randomized block design with three replications. Results showed an effective increasing of the grain yield provided by the recommendation of new cultivars from different Brazilian breeding programs in the past five decades. In addition, the GxE analysis interaction indicated that cultivars recommended after the year
2005 were those with high average grain yield, wide adaptability and high predictability.

Key words: Phaseolus vulgaris L., breeding, GxE, increase in productivity.

\section{INTRODUÇ̃̃̃O}

O feijão é uma cultura de grande importância socioeconômica para o Brasil e, na safra 2012/2013, alcançou uma produção de 2,8 milhões de toneladas (CONAB, 2013). É cultivado em quase todos os Estados brasileiros, em diferentes sistemas de cultivo e épocas de semeadura, submetendo a cultura a diversas condições ambientais (PEREIRA et al., 2009). O feijão preto ocupa o segundo lugar no tipo de grão mais cultivado no país, sendo muito consumido nos Estados do Sul, Rio de Janeiro, Sudeste de Minas Gerais e Sul do Espírito Santo (VIEIRA, 2005).

Nas principais regiões produtoras de feijão, o cultivo é realizado em três épocas distintas de plantio (safra das águas, da seca e de inverno), de acordo com o zoneamento agroclimático de cada região (MELO et al., 2007). É também nessas regiões que se concentram os principais programas de melhoramento de feijão, nos quais há uma busca contínua por novas cultivares, mais produtivas, menos sensíveis aos estresses bióticos e abióticos

\footnotetext{
'Programa de Pós-graduação em Genética e Melhoramento (PPGGM), Universidade Federal de Viçosa (UFV), Viçosa, MG, Brasil.

IICurso de Agronomia, UFV, Viçosa, MG, Brasil.

IIIDepartamento de Fitotecnia, UFV, Viçosa, MG, Brasil.

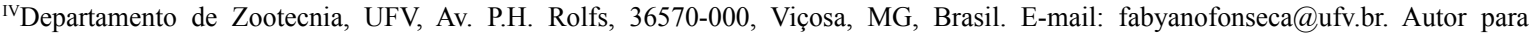
correspondência.

${ }^{\mathrm{v}}$ Departamento de Biologia, UFV, Viçosa, MG, Brasil. 
e com características que atendam ao mercado consumidor. Esse processo incessantemente de melhoramento culminou no lançamento de centenas de cultivares, nas quais evoluíram características como arquitetura da planta, resistência a doenças e tipo comercial de grão, aliadas à alta produtividade (MELO et al., 2007).

$\mathrm{Na}$ etapa final de um programa de melhoramento, as linhagens são avaliadas em redes nos ensaios de Valor de Cultivo e Uso (VCUs), em um grande número de ambientes que representam as diversas condições ambientais nas quais uma cultivar poderá ser submetida (PEREIRA et al., 2009). Nesses ensaios, a presença da interação genótipos $\mathrm{x}$ ambientes dificulta o trabalho dos melhoristas, pois resulta no comportamento variável dos genótipos sobre os diferentes ambientes, dificultando a seleção (CARGNIN et al., 2006). Porém, a análise de estabilidade e adaptabilidade é uma alternativa para amenizar os efeitos da interação e identificar cultivares com comportamento previsível e responsivas às melhorias do ambiente (CRUZ \& REGAZZI, 2001). Tal estimação fornece informações detalhadas sobre o comportamento das cultivares e contribui na sua caracterização quanto à resposta às variações ambientais, proporcionando maior segurança na recomendação (SILVA et al., 2013).

Diferentes metodologias foram propostas para a análise da adaptabilidade e estabilidade, de forma que a escolha por uma delas depende de fatores como a quantidade de genótipos e de ambientes avaliados e da forma com que a interpretação dos resultados será realizada. Na cultura do feijão, estudos desta natureza já foram realizados por OLIVEIRA et al. (2006); RIBEIRO et al. (2008), PEREIRA et al. (2009) e SILVA et al. (2013), entre outros. Entretanto, a maioria dos genótipos estudados são linhagens de um determinado programa de melhoramento, as quais, muitas vezes, não chegam a serem lançadas comercialmente. Além disso, entre os trabalhos que contemplam cultivares, estes avaliam um número reduzido de genótipos, os quais pertencem geralmente a apenas um determinado período cronológico do melhoramento genético de feijão.

Diante do exposto, torna-se interessante reunir em um único trabalho as principais cultivares recomendadas e cultivadas ao longo da história do melhoramento genético do feijão no Brasil, por diferentes instituições de pesquisa. Além disso, é importante estimar os parâmetros de adaptabilidade e estabilidade fenotípica e, assim, investigar a contribuição do melhoramento no aumento da produtividade de grãos e na adaptação e previsibilidade de comportamento das cultivares.
Dessa forma, o objetivo deste trabalho foi estudar os parâmetros de adaptabilidade e estabilidade fenotípica e avaliar o incremento na produtividade de grãos em genótipos de feijão preto, desenvolvidos pelos programas brasileiros de melhoramento genético, entre os anos de 1960 a 2013.

\section{MATERIAL E MÉTODOS}

Os experimentos foram conduzidos nas Estações Experimentais da Universidade Federal de Viçosa, nos municípios de Viçosa/MG (latitude: $20^{\circ} 45^{\prime} 14^{\prime \prime} \mathrm{S}$, longitude: $42^{\circ} 52^{\prime} 55^{\prime}$ ' W e altitude: $648 \mathrm{~m}$ ) e Coimbra/MG (latitude $20^{\circ} 51^{\prime} 24^{\prime \prime}$ S e a uma longitude $42^{\circ} 48^{\prime} 10^{\prime \prime} \mathrm{W}$ e altitude de 720 metros), nas safras da seca e de inverno 2013.

Neste estudo, foram utilizadas 38 cultivares e duas linhagens de feijão do grupo comercial preto (Tabela 1). A decisão sobre as cultivares utilizadas no estudo foi realizada por meio de registros científicos (artigos em periódicos indexados) e relatos de sua experiência de melhoristas de diferentes programas de melhoramento de feijão. Inicialmente, uma amostra de sementes das cultivares foi obtida junto às instituições obtentoras e, em seguida, multiplicada para homogeneizar a germinação e posterior realização do experimento.

O delineamento experimental utilizado foi o de blocos ao acaso com três repetições. As parcelas experimentais foram constituídas de quatro linhas de três metros de comprimento, espaçadas 0,5 metros entre elas. A característica utilizada para o estudo foi produtividade de grãos, obtida pela pesagem em gramas das duas fileiras centrais da parcela, ajustada a $13 \%$ de umidade e extrapoladas para $\mathrm{kg} \mathrm{ha}^{-1}$.

Os resultados foram submetidos às análises de variância individual de cada ambiente, seguida da análise de variância conjunta. A análise de variância conjunta foi realizada pelo modelo de blocos casualizados, constituído de efeitos aleatórios para genótipos, para ambiente e para a interação de genótipos $x$ ambientes. O modelo dessa análise é dado por:

$$
Y_{i j k}=m+G_{i}+B / A_{j k}+A_{k}+G A_{i k}+E_{i j k}
$$

em que: $Y_{i j k}$ é o valor observado da característica no genótipo $i$ no bloco $j(\mathrm{j}=1,2,3)$ e dentro do ambiente $k ; m$ é a média geral; $G_{i}$ é o efeito aleatório do genótipo $i$ ( $\mathrm{i}=1,2,3, \ldots, 40) ; B / A_{j k,}$ o efeito aleatório do bloco $j$ dentro do ambiente $k$; $A_{k}$ é o efeito aleatório do ambiente $k(\mathrm{k}=1,2,3,4) ; G A_{i k}$ é o efeito aleatório da interação do genótipo $i$ com o ambiente $k ; E_{i j k}$ é o erro experimental.

Ciência Rural, v.45, n.11, nov, 2015. 
Tabela 1 - Nome, ano de recomendação (Ano rec.), instituição responsável, média de produtividade de grãos $\left(\mathrm{kg}\right.$ ha $\left.{ }^{-1}\right)$ por ambiente e teste de agrupamento de médias das 40 cultivares de feijão do grupo comercial preto avaliadas em Minas Gerais, 2013.

\begin{tabular}{|c|c|c|c|c|c|c|}
\hline \multirow{2}{*}{ Cultivares } & \multirow{2}{*}{ Ano rec. } & \multirow{2}{*}{ Instituição } & \multicolumn{4}{|c|}{------- Seca/2013 ------------ ---------- Inverno/2013 ----- } \\
\hline & & & Coimbra & Viçosa & Coimbra & Viçosa \\
\hline 'VP 22' & 2013 & UFV & $4866 \mathrm{a}$ & $3608 \mathrm{a}$ & $4142 \mathrm{a}$ & $3197 \mathrm{a}$ \\
\hline ‘IPR Tuiuiú’ & 2010 & IAPAR & 4588 a & 3923 a & 4014 a & $3202 \mathrm{a}$ \\
\hline 'BRS Supremo' & 2004 & Embrapa & 4293 a & $2845 \mathrm{c}$ & $3165 \mathrm{c}$ & $2585 \mathrm{c}$ \\
\hline 'IPR Tiziu’ & 2006 & IAPAR & $4234 \mathrm{a}$ & $3350 \mathrm{~b}$ & $3370 \mathrm{c}$ & $2904 \mathrm{~b}$ \\
\hline 'Diamante Negro' & 1991 & Embrapa & $4223 \mathrm{a}$ & $2990 \mathrm{~b}$ & $3282 \mathrm{c}$ & $2136 \mathrm{~d}$ \\
\hline 'BRS Campeiro’ & 2003 & Embrapa & $4205 \mathrm{a}$ & $3194 \mathrm{~b}$ & $3519 \mathrm{c}$ & $2446 \mathrm{c}$ \\
\hline 'BRS Expedito' & 2007 & Embrapa & $4150 \mathrm{a}$ & $3168 \mathrm{~b}$ & $3389 \mathrm{c}$ & $2570 \mathrm{c}$ \\
\hline 'IAC Tunã' & 2005 & IAC & $4046 \mathrm{~b}$ & $3368 \mathrm{~b}$ & $3713 b$ & $2866 \mathrm{~b}$ \\
\hline 'IPR Gralha' & 2006 & IAPAR & $4020 \mathrm{~b}$ & $2752 \mathrm{c}$ & $3665 \mathrm{~b}$ & $2515 \mathrm{c}$ \\
\hline 'VP 33' & 2013 & UFV & $3983 \mathrm{~b}$ & $3525 \mathrm{~b}$ & $3710 \mathrm{~b}$ & 2949 b \\
\hline 'BRS Grafite' & 2003 & Embrapa & $3849 \mathrm{~b}$ & $3244 \mathrm{~b}$ & $3250 \mathrm{c}$ & $2507 \mathrm{c}$ \\
\hline 'BRS Valente' & 2001 & Embrapa & $3837 \mathrm{~b}$ & $3362 \mathrm{~b}$ & $3043 \mathrm{c}$ & $2395 \mathrm{c}$ \\
\hline 'IPR Uirapurú' & 2000 & IAPAR & $3834 \mathrm{~b}$ & $3035 \mathrm{~b}$ & $3275 \mathrm{c}$ & $2397 \mathrm{c}$ \\
\hline 'BRS Esplendor' & 2006 & Embrapa & $3756 \mathrm{~b}$ & $3459 \mathrm{~b}$ & $3505 \mathrm{c}$ & $2800 \mathrm{~b}$ \\
\hline 'IPR Graúna’ & 2002 & IAPAR & $3524 \mathrm{~b}$ & $3069 \mathrm{~b}$ & $3238 \mathrm{c}$ & $2443 \mathrm{c}$ \\
\hline 'IAC - Una' & 1994 & IAC & $3518 \mathrm{~b}$ & $3252 \mathrm{~b}$ & $3164 \mathrm{c}$ & $2260 \mathrm{~d}$ \\
\hline 'Ouro Negro' & 1992 & Embrapa & $3384 \mathrm{~b}$ & $2504 \mathrm{c}$ & $2501 \mathrm{~d}$ & $2184 \mathrm{~d}$ \\
\hline 'IAPAR 65’ & 1993 & IAPAR & $3202 \mathrm{c}$ & $2281 \mathrm{c}$ & $2580 \mathrm{~d}$ & $1811 \mathrm{~d}$ \\
\hline 'Varre - Sai' & 1991 & PSAGRO/RJ & $3069 \mathrm{c}$ & $2669 \mathrm{c}$ & $2671 \mathrm{~d}$ & $1884 \mathrm{~d}$ \\
\hline 'Xamego' & 1993 & EMGOPA & $2898 \mathrm{c}$ & $2813 \mathrm{c}$ & $2454 \mathrm{~d}$ & $1830 \mathrm{~d}$ \\
\hline 'Capixaba Precoce' & 1980 & EMCAPA & $2883 \mathrm{c}$ & $2724 \mathrm{c}$ & $2023 \mathrm{~d}$ & $1825 \mathrm{~d}$ \\
\hline 'Onix’' & 1992 & EMGOPA & $2843 \mathrm{c}$ & $2622 \mathrm{c}$ & $2386 \mathrm{~d}$ & $1694 \mathrm{~d}$ \\
\hline 'BR - IPA 10' & 1992 & IPA & $2821 \mathrm{c}$ & $2789 \mathrm{c}$ & $2490 \mathrm{~d}$ & $1863 \mathrm{~d}$ \\
\hline 'BR1 - Xodó’' & 1985 & PESAGRO & $2806 \mathrm{c}$ & $2458 \mathrm{c}$ & $2605 \mathrm{~d}$ & $1897 \mathrm{~d}$ \\
\hline 'BR-IPAGRO 2'- Pampa & 1989 & EMCAPA & $2796 \mathrm{c}$ & $2577 \mathrm{c}$ & $2772 \mathrm{~d}$ & $1725 \mathrm{~d}$ \\
\hline 'Iapar 8' - Rio Negro & 1983 & IAPAR & $2787 \mathrm{c}$ & $2271 \mathrm{c}$ & $2337 \mathrm{~d}$ & $1943 \mathrm{~d}$ \\
\hline 'BR 6' - Barriga verde & 1990 & EMPASC & $2781 \mathrm{c}$ & $2813 \mathrm{c}$ & $2310 \mathrm{~d}$ & $1776 \mathrm{~d}$ \\
\hline 'BR-IPAGRO1'-Macanudo & 1989 & IPAGRO & $2739 \mathrm{c}$ & $2625 \mathrm{c}$ & $2680 \mathrm{~d}$ & $1804 \mathrm{~d}$ \\
\hline 'FT 120' & 1986 & FT-sementes & $2711 \mathrm{c}$ & $2640 \mathrm{c}$ & $2581 \mathrm{~d}$ & $1815 \mathrm{~d}$ \\
\hline 'Moruna' & 1980 & IAC & $2610 \mathrm{c}$ & $2634 \mathrm{c}$ & $2294 \mathrm{~d}$ & $1984 \mathrm{~d}$ \\
\hline 'IAPAR 44’ & 1990 & IAPAR & $2580 \mathrm{c}$ & $2788 \mathrm{c}$ & $2570 \mathrm{~d}$ & $1783 \mathrm{~d}$ \\
\hline 'Milionário 1732’ & 1983 & EPAMIG & $2547 \mathrm{c}$ & $2752 \mathrm{c}$ & $2473 d$ & $1965 \mathrm{~d}$ \\
\hline 'Preto Uberabinha' & 1990 & IPEACO/MG & $2547 \mathrm{c}$ & $2469 \mathrm{c}$ & $2506 \mathrm{~d}$ & $1789 \mathrm{~d}$ \\
\hline 'Iraí' & 1981 & IPAGRO & $2529 \mathrm{c}$ & $2671 \mathrm{c}$ & $2635 d$ & $1869 \mathrm{~d}$ \\
\hline ‘IAPAR 20’ & 1987 & IAPAR & $2509 \mathrm{c}$ & $2771 \mathrm{c}$ & $2560 \mathrm{~d}$ & $1896 \mathrm{~d}$ \\
\hline 'Rio Tibagi' & 1971 & UFV & $2502 \mathrm{c}$ & $2687 \mathrm{c}$ & $2496 \mathrm{~d}$ & $1924 \mathrm{~d}$ \\
\hline 'Rico 1735' & 1983 & EPAMIG & $2408 \mathrm{c}$ & $2667 \mathrm{c}$ & $2341 \mathrm{~d}$ & $1869 \mathrm{~d}$ \\
\hline 'BR - 3' Ipanema & 1985 & PESAGRO & $2381 \mathrm{c}$ & $2524 \mathrm{c}$ & $2375 d$ & $1825 \mathrm{~d}$ \\
\hline 'Rico 23' & 1960 & UFV & $2379 \mathrm{c}$ & $3129 \mathrm{~b}$ & $2645 \mathrm{~d}$ & $1776 \mathrm{~d}$ \\
\hline 'BR - 2' Grande Rio & 1985 & PESAGRO & $2190 \mathrm{c}$ & $2832 \mathrm{c}$ & $2507 \mathrm{~d}$ & $1844 \mathrm{~d}$ \\
\hline Média & - & - & 3246 & 2896 & 2880 & 2169 \\
\hline CV (\%) & - & - & 10,84 & 11,71 & 8,83 & 8,86 \\
\hline
\end{tabular}

${ }^{*}$ Médias seguidas de mesma letra na coluna pertencem a um mesmo grupo, de acordo com o critério de agrupamento de Scott-Knott (1974), a $5 \%$ de probabilidade.

Para avaliar a homogeneidade das variâncias residuais no presente modelo, utilizou-se a razão entre o maior e menor quadrado médio residual dos ensaios. Por meio do teste $\mathrm{F}_{\max }$, as variâncias serão consideradas homogêneas quando esta razão for menor que 7,0 (PIMENTEL-GOMES, 1990). Após a verificação da significância da interação, as médias de produtividade de grãos das cultivares 
foram submetidas ao teste de agrupamento de SCOTT-KNOTT (1974) a 5\% de probabilidade de erro, em cada um dos ambientes, a fim de verificar o agrupamento diferencial entre os genótipos.

Para o estudo da adaptabilidade e estabilidade, foi utilizada a metodologia proposta por EBERHART \& RUSSELL (1966), a qual baseia-se na análise de regressão linear, em que genótipos com adaptabilidade geral ou ampla são aqueles com $\beta_{1 i}=1$; genótipos com adaptabilidade específica a ambientes favoráveis são aqueles com $\beta_{1 i}>1$; e genótipos com adaptabilidade específica a ambientes desfavoráveis são aqueles com $\beta_{1 i}<1$. A estabilidade é avaliada pelos desvios de regressão $\left(\sigma_{d i}^{2}\right)$, e considerados genótipos com previsibilidade de comportamento aqueles com $\sigma_{d i}^{2}=0$ e genótipos de comportamentos imprevisíveis aqueles com $\sigma_{d i}^{2} \neq 0$. Todas as análises foram processadas no software Genes (CRUZ, 2006).

\section{RESULTADOS E DISCUSSÃO}

A estimativa obtida pela razão entre o maior e o menor quadrado médio dos resíduos foi inferior a sete $(3,36)$, indicando homogeneidade das variâncias residuais, possibilitando a análise conjunta, a qual revelou efeito significativo para todas as fontes de variação testadas (P-valor<0,001) (Tabela 1). O efeito significativo da interação cultivares $\mathrm{x}$ ambientes revela que as cultivares têm resposta diferenciada em relação às mudanças de ambiente. Essa alteração ocorre devido às condições edafoclimáticas diferentes dos locais e safras de avaliação (RIBEIRO et al., 2008) e também da estrutura genética diferenciada dos genótipos estudados. Nos estudos de OLIVEIRA et al. (2006); MELO et al. (2007); RIBEIRO et al. (2008) e MOURA et al. (2013), também foi observada resposta diferenciada na produtividade de grãos de genótipos de feijão, quando submetidos ao cultivo em diferentes ambientes. A média geral de produtividade de grãos foi de $2797 \mathrm{~kg} \mathrm{ha}^{-1} \mathrm{e}$ o coeficiente de variação observado de $10,45 \%$, estando dentro dos padrões para a cultura do feijão. Em estudos com feijão, OLIVEIRA et al. (2006), CARBONELL et al. (2010) e SILVA et al. (2013) encontraram CVs entre 6 e $23 \%$ para produtividade de grãos.

Uma vez constatada a interação $\mathrm{G}$ x A significativa, os resultados foram discutidos separadamente por ambiente. As médias gerais de produtividade de grãos variaram entre os experimentos (Tabela 2). No ambiente de Coimbra, na safra da seca, foi observada a maior Prod. (3246kg ha-1) e, no ambiente de Viçosa, na safra de inverno, a menor $\left(2169 \mathrm{~kg} \mathrm{ha}^{-1}\right)$. Esses resultados corroboram os observados por OLIVEIRA et al. (2006), que
Tabela 2 - Resumo da análise de variância conjunta referentes a produtividade de grãos em $\mathrm{kg} \mathrm{ha}^{-1}$ avaliada em 40 cultivares de feijão do grupo comercial preto. Coimbra e Viçosa, Minas Gerais, safras da Seca e de inverno de 2013.

\begin{tabular}{llll}
\hline $\begin{array}{l}\text { Fontes de } \\
\text { Variação }\end{array}$ & GL & QM & P-valor \\
\hline Blocos/Amb & 8 & 353991 & \\
Cultivares (C) & 39 & 2931357 & $<0,001$ \\
Ambientes (A) & 3 & 24518296 & $<0,001$ \\
Cult x Amb & 117 & 190032 & $<0,001$ \\
Resíduo & 312 & 85088 & \\
Média Geral & - & 2797 & \\
CV $(\%)$ & - & 10,45 & \\
\hline
\end{tabular}

GL: Graus de liberdade; QM: Quadrado Médio.

avaliaram linhagens de feijão em Viçosa e Coimbra/ MG e obtiveram as menores médias em Viçosa. A variabilidade genética significativa entre as cultivares pode ser corroborada pelo teste de SCOTT \& KNOTT ( $5 \%$ de probabilidade), o qual proporcionou a formação de diferentes grupos em cada um dos ambientes.

Em Coimbra, na safra da seca, com exceção da cultivar 'Diamante Negro' (1991), no primeiro grupo (a), e das cultivares 'IAC - Una' (1994) e 'Ouro Negro' (1992), no segundo grupo (b), as demais cultivares pertencentes a estes grupos foram recomendadas após o ano de 2000. Cabe observar que a maioria dessas cultivares (grupos "a' e "b") foram recomendadas há menos de 10 anos, demostrando o compromisso dos melhoristas no lançamento constante de cultivares superiores quanto à produtividade de grãos. Em contrapartida, as cultivares recomendadas entre 1960 e 1993 apresentaram comportamento inferior às demais, sendo alocadas conjuntamente no grupo "c" (Tabela 2).

Em Viçosa, nas safras da seca e de inverno 2013, e, em Coimbra/inverno 2013, o agrupamento entre as cultivares foi semelhante ao ocorrido em Coimbra/seca 2013 (Tabela 2), visto que os genótipos mais produtivos e que estão no grupo "a" são IPR Tuiuiú e VP 22, ambos desenvolvidos nos últimos anos (2010 e 2013 respectivamente). Quanto às cultivares dos demais grupos, observa-se uma troca de posições entre grupos. Entretanto, cabe salientar que as cultivares com as piores performances (grupos "c" e "d") foram as recomendadas, em geral, antes do ano de 1990, corroborando a recomendação de cultivares com maiores potenciais produtivos ano após ano.

Quando se analisa a média geral de cada uma das cultivares, nos quatro ambientes, fica ainda mais evidente a superioridade das cultivares recomendadas após o ano de 2000, visto que estas apresentaram médias superiores à média geral $(2797 \mathrm{~kg}$ 
$\mathrm{ha}^{-1}$ ) e foram alocadas em grupos distintos ("a" e "b"), ao contrário das cultivares recomendadas entre $1960 \mathrm{e}$ 2000, aproximadamente, que apresentaram as menores médias e foram alocadas no grupo "c" (Tabela 3).

Os aumentos mais expressivos observados nas últimas décadas reflete uma maior ação das instituições de pesquisa do Brasil em atividades ligadas ao melhoramento genético do feijoeiro, com envolvimento de especialistas de diferentes áreas do conhecimento (melhoramento, fitopatologia, biotecnologia, estatística, etc.). $\mathrm{O}$ desenvolvimento de cultivares resistente a estresses bióticos e abióticos,

Tabela 3 - Produtividade média de grãos, parâmetros de adaptabilidade e estabilidade fenotípica (coeficiente de regressão $\left(\beta_{1 i}\right)$ e desvios da regressão $\left(\sigma_{\mathrm{di}}^{2}\right)$ ), segundo critérios de EBERHART \& RUSSELL (1966) das cultivares de feijão avaliadas em Minas Gerais/2013.

\begin{tabular}{|c|c|c|c|c|c|}
\hline Genótipo & Recomendação & Média $\left(\mathrm{kg} \mathrm{ha}^{-1}\right)$ & $\beta_{1}$ & $\sigma_{\mathrm{di}}^{2}$ & $\mathrm{R}^{2}(\%)$ \\
\hline 'VP 22' & 2013 & $3954 \mathrm{a}$ & 1,413 & $139519,9^{* *}$ & 78 \\
\hline 'IPR Tuiuiú' & 2010 & 3932 a & 1,238 & $-13219,3^{\mathrm{NS}}$ & 97 \\
\hline 'VP 33' & 2013 & $3542 \mathrm{~b}$ & 0,951 & $-18148,1^{\mathrm{NS}}$ & 96 \\
\hline 'IAC Tunã' & 2005 & $3498 \mathrm{~b}$ & 1,057 & $10464,04^{\mathrm{NS}}$ & 90 \\
\hline 'IPR Tiziu’ & 2006 & $3464 \mathrm{~b}$ & 1,106 & $60712,97^{\mathrm{NS}}$ & 81 \\
\hline 'BRS Esplendor' & 2006 & $3380 \mathrm{~b}$ & 0,900 & $-26592,7^{\mathrm{NS}}$ & 99 \\
\hline 'BRS Campeiro' & 2003 & $3341 \mathrm{~b}$ & $1,550^{* *}$ & $35393,0^{\mathrm{NS}}$ & 92 \\
\hline 'BRS Expedito' & 2007 & $3319 b$ & 1,361 & $43475,54^{\mathrm{NS}}$ & 89 \\
\hline 'IPR Gralha' & 2006 & $3238 \mathrm{~b}$ & 1,293 & $235507,7^{* *}$ & 66 \\
\hline 'BRS Supremo' & 2004 & $3222 b$ & 1,368 & $247196,3^{* *}$ & 68 \\
\hline 'BRS Grafite' & 2003 & $3212 b$ & 1,199 & $-16538,4^{\mathrm{NS}}$ & 97 \\
\hline 'BRS Valente' & 2001 & $3159 \mathrm{~b}$ & 1,296 & $5564,498^{\mathrm{NS}}$ & 94 \\
\hline 'Diamante Negro' & 1991 & $3158 \mathrm{~b}$ & $1,817^{* *}$ & $71105,55^{*}$ & 91 \\
\hline 'IPR Uirapurú' & 2000 & $3135 \mathrm{~b}$ & 1,271 & $7910,569^{\mathrm{NS}}$ & 93 \\
\hline 'IPR Graúna’ & 2002 & $3069 \mathrm{~b}$ & 0,998 & $-19789,4^{\mathrm{NS}}$ & 97 \\
\hline 'IAC-Una' & 1994 & $3049 \mathrm{~b}$ & 1,201 & $-21731,9^{\mathrm{NS}}$ & 99 \\
\hline 'Ouro Negro' & 1992 & $2643 \mathrm{c}$ & 0,971 & $82352,0^{*}$ & 72 \\
\hline 'Varre-Sai' & 1991 & $2573 \mathrm{c}$ & 1,098 & $-28254,9^{\mathrm{NS}}$ & 100 \\
\hline 'Xamego' & 1993 & $2499 \mathrm{c}$ & 1,022 & $4887,159^{\mathrm{NS}}$ & 91 \\
\hline 'BR - IPA 10' & 1992 & $2491 \mathrm{c}$ & 0,933 & $653,5671^{\mathrm{NS}}$ & 90 \\
\hline 'Rico 23' & 1960 & $2482 \mathrm{c}$ & 0,775 & $264464,3^{* *}$ & 39 \\
\hline 'IAPAR 65 ' & 1993 & $2468 \mathrm{c}$ & 1,196 & $42405,65^{\mathrm{NS}}$ & 86 \\
\hline 'BR - IPAGRO 2' - Pampa & 1989 & $2468 \mathrm{c}$ & 1,061 & $8625,063^{\mathrm{NS}}$ & 90 \\
\hline 'BR-IPAGRO 1'- Macanudo & 1989 & $2462 \mathrm{c}$ & 0,933 & $-3525,43^{\mathrm{NS}}$ & 91 \\
\hline 'BR 1'- Xodó & 1985 & $2441 \mathrm{c}$ & 0,850 & $-21609,3^{\mathrm{NS}}$ & 97 \\
\hline 'FT 120' & 1986 & $2437 \mathrm{c}$ & 0,891 & $-9570,9^{\mathrm{NS}}$ & 93 \\
\hline 'Milionário 1732' & 1983 & $2434 \mathrm{c}$ & 0,620 & $21392,86^{\mathrm{NS}}$ & 70 \\
\hline 'IAPAR 20’ & 1987 & $2434 \mathrm{c}$ & 0,678 & $42920,22^{\mathrm{NS}}$ & 66 \\
\hline 'IAPAR 44' & 1990 & $2430 \mathrm{c}$ & 0,850 & $44558,8^{\mathrm{NS}}$ & 75 \\
\hline 'Iraí' & 1981 & $2426 \mathrm{c}$ & 0,715 & $27398,18^{\mathrm{NS}}$ & 74 \\
\hline 'BR 6' - Barriga verde & 1990 & $2420 \mathrm{c}$ & 0,973 & $37293,4^{\mathrm{NS}}$ & 82 \\
\hline 'Rio Tibagi' & 1971 & $2402 \mathrm{c}$ & 0,622 & $17258,62^{\mathrm{NS}}$ & 72 \\
\hline 'Onix’' & 1992 & $2386 \mathrm{c}$ & 1,082 & $-15506,9^{\mathrm{NS}}$ & 97 \\
\hline 'Moruna' & 1980 & $2380 \mathrm{c}$ & 0,604 & $771,0531^{\mathrm{NS}}$ & 79 \\
\hline 'Capixaba Precoce' & 1980 & $2364 \mathrm{c}$ & 0,944 & $101373,1^{*}$ & 68 \\
\hline 'BR - 2' Grande Rio & 1985 & $2343 \mathrm{c}$ & 0,501 & $163867,1^{* *}$ & 29 \\
\hline 'Iapar 8' - Rio Negro & 1983 & $2334 \mathrm{c}$ & 0,722 & $-7341,1^{\mathrm{NS}}$ & 88 \\
\hline 'Preto Uberabinha' & 1990 & $2328 \mathrm{c}$ & 0,760 & $-10361,8^{\mathrm{NS}}$ & 91 \\
\hline 'Rico 1735' & 1983 & $2321 \mathrm{c}$ & $0,586^{*}$ & $32459,87^{\mathrm{NS}}$ & 63 \\
\hline 'BR - 3' Ipanema & 1985 & $2276 \mathrm{c}$ & 0,593 & $6773,24^{\mathrm{NS}}$ & 75 \\
\hline Média Geral & - & 2797 & - & - & - \\
\hline
\end{tabular}

*Médias seguidas por letras distintas diferem entre si $(\mathrm{P}<0,05)$ pelo teste de Scott e Knott (1974),

ns, * $\mathrm{e}^{* *}$ : não significativo, significativo a 5 e $1 \%$, pelo teste $\mathrm{t}\left(\mathrm{h}_{0}: \beta_{1 \mathrm{i}}=1,0\right)$ e pelo teste $\mathrm{F}\left(\mathrm{h}_{0}: \sigma_{\mathrm{di}}^{2}\right)$

Ciência Rural, v.45, n.11, nov, 2015. 
adaptadas a diferentes locais de cultivo, com elevada estabilidade de produção e responsivas as melhorias de ambiente é o fato responsável pelo incremento observado na produtividade. Segundo RAMALHO (2012), houve grande progresso na produtividade do feijão no país, o que pode ser atribuído ao melhoramento genético. Como evidência, temos os estudos sobre progresso genético realizados por ABREU et al. (1994), MATOS (2007), CHIORATO et al. (2010) e FARIA et al. (2014), os quais obtiveram ganhos genéticos entre 1,07 a $3,26 \%$ ao ano.

A significância da interação $\mathrm{G}$ x A indicou comportamento diferenciado dos genótipos frente às variações ambientais, sendo essencial sua avaliação detalhada no melhoramento, pois há a possibilidade de um genótipo se destacar em um determinado ambiente e não em outro. Por tal motivo, é necessário o estudo dos parâmetros de adaptabilidade e estabilidade.

Ao analisar os fatores de adaptabilidade e estabilidade fenotípica pelo critério de EBERHART \& RUSSELL (1966), verifica-se que $92,5 \%$ das cultivares apresentaram ampla adaptabilidade, isso porque obtiveram coeficientes de regressão estatisticamente iguais a $1\left(\beta_{1 \mathrm{i}}=1\right)$ (Tabela 3$)$. As cultivares 'Diamante Negro' e 'BRS Campeiro' demostraram adaptabilidade a ambientes favoráveis $(\beta>1)$, ou seja, respondem favoravelmente as melhorias do ambiente, sendo indicadas para áreas com emprego de alta tecnologia. Por outro lado, a cultivar 'Rico 1735' apresentou $\beta_{1}$ estatisticamente inferior à unidade $(\beta<1)$, evidenciando ser adaptada a ambientes desfavoráveis, não apresentando incremento na produtividade de grãos com a melhoria do ambiente, devendo ser recomendada para áreas de baixa tecnologia.

Quanto à estabilidade fenotípica, $80 \%$ das cultivares apresentaram desvio de regressão igual a zero $\left(\sigma_{\mathrm{di}}^{2}=0\right)$, indicando alta previsibilidade de comportamento (Tabela 3). Em contrapartida, a linhagem VP 22 e as cultivares 'IPR Gralha', 'BRS Supremo', 'Diamante Negro', 'Ouro Negro', 'Rico 23', 'Capixaba Precoce' e 'BR - 2 Grande Rio' apresentaram desvios de regressão significativos $\left(\sigma_{\mathrm{di}}^{2} \neq 0\right)$, evidenciando comportamento imprevisível nos ambientes, ou seja, possuem constituição genética de baixa estabilidade. Entre tais cultivares, apenas 'BRS Supremo' e 'IPR Gralha' e a linhagem 'VP 22' foram desenvolvidas após o ano de 2000, demonstrando o compromisso dos programas de melhoramento de feijão em colocar à disposição dos produtores cultivares com alta estabilidade de produção.

Considerando os resultados obtidos pela análise de EBERHART \& RUSSEL simultaneamente com as médias de produtividade de grãos das cultivares, verifica-se que a maioria dos genótipos mostraram alta previsibilidade de comportamento e ampla adaptabilidade. Além disso, as cultivares 'BRS Valente', 'BRS Grafite', 'BRS Esplendor', 'BRS Expedito', 'IAC-Una', 'IPR Uirapurú', 'IPR Tiziu', 'IPR Graúna', 'IAC Tunã', 'IPR Tuiuiú' e a linhagem 'VP 33' merecem destaque, pois apresentaram conjuntamente a esses parâmetros, produtividade de grãos superior à média geral $\left(2797 \mathrm{~kg} \mathrm{ha}^{-1}\right)$. Com exceção da cultivar 'IAC-Una', as demais supracitadas foram lançadas nas últimas duas décadas (2000/2010). Tal fato comprova a recomendação contínua de cultivares que agregam alta produtividade, adaptação a uma diversidade de condições climáticas e comportamento previsível, culminando em expressivo progresso genético. Além disso, esses genótipos revelaram altos coeficientes de determinação $\left(R^{2}>75 \%\right)$, indicando que grande parte de suas variações totais são explicadas pelo modelo adotado (Tabelas 3).

A criação de novas cultivares têm sido uma das tecnologias que mais contribuiu para o aumento da produtividade e estabilidade de produção sem custos adicionais ao agricultor (POLIZEL et al., 2013). Considerando que os genótipos mais adaptados e estáveis serão também os mais produtivos (PEREIRA et al., 2009), acredita-se que os programas de melhoramento de feijão têm cumprido seu papel na recomendação de cultivares promissoras quanto à produtividade de grãos e adaptabilidade e estabilidade fenotípica.

\section{CONCLUSÃo}

Os programas de melhoramento genético do feijão têm contribuído efetivamente para o incremento na produtividade de grãos com o lançamento de cultivares de grãos preto com elevado potencial produtivo.

As cultivares que melhor associam o fenótipo, médias altas de produtividade de grãos, adaptabilidade ampla e alta previsibilidade de comportamento foram as recomendadas entre os anos de 2000 e 2013.

\section{AGRADECIMENTOS}

Os autores agradecem a Embrapa Arroz e Feijão, ao Instituto Agronômico do Paraná (IAPAR) e ao Instituto Agronômico de Campinas (IAC) pelo auxilio na aquisição das cultivares avaliadas. Agradecemos também ao Conselho Nacional de Desenvolvimento Científico e Tecnológico (CNPq) e a Fundação de Amparo à Pesquisa do estado de Minas Gerais (FAPEMIG) pela concessão do apoio financeiro.

\section{REFERENCIAS}

ABREU, A.F.B. et al. Progresso do melhoramento genético do feijoeiro nas décadas de setenta e oitenta nas regiões Sul e Alto Paranaíba em 
Minas Gerais. Pesquisa Agropecuária Brasileira, v.29, n.1, p.105112, 1994. Disponível em: <https://seer.sct.embrapa.br/index.php/pab/ article/viewFile/4033/1324>. Acesso em: 11 set. 2014.

CARBONELL, S.A.M. et al. Tamanho de grão comercial em cultivares de feijoeiro. Ciência Rural, v.40, n.10, p.2067-2073, 2010. Disponível em: <http://www.scielo.br/pdf/cr/v40n10/a 731cr3346.pdf>. Acesso em: 12 set. 2014

CARGNIN, A. et al. Interação entre genótipos e ambientes e implicações em ganhos com seleção em trigo. Pesquisa Agropecuária Brasileira, v.41, n.6, p.987-993, 2006. Disponível em: <http://www. scielo.br/pdf/pab/v41n6/30865.pdf>. Acesso em: 11 set. 2014.

CONAB (COMPANHIA NACIONAL DE ABASTECIMENTO) Acompanhamento de safra brasileira: grãos, sexto levantamento, março 2014. Disponível em: <http://www.conab.gov.br/ OlalaCMS/uploads/arquivos/13_07_09_09_04_53_boletim_ graos_junho_2013.pdf>. Acesso em: 10 set. 2014 .

CHIORATO, A.F. et al. Genetic gain in the breeding program of common beans at IAC from 1989 to 2007. Crop Breeding and Applied Biotechnology, v.10, p.329-336, 2010. Disponível em: <http://www. scielo.br/pdf/cbab/v10n4/a07v10n4.pdf>. Acesso em: 11 set. 2014.

CRUZ, C.D.; REGAZZI, A.J. Modelos biométricos aplicados ao melhoramento genético. Viçosa: UFV, 2001. 390p.

CRUZ, C.D. Programa genes: biometria. Viçosa, UFV, 2006. 286p.

EBERHART, S.A.; RUSSELL, W.A. Stability parameters for comparing varieties. Crop Science, v.6, p.36-40, 1966. Disponível em: <http://www.sap.uchile.cl/descargas/fisiogenetica/ Stability\%20parameters\%20for\%20comparing\%20varieties Eberhart Russell1966.pdf>. Acesso em: 11 set. 2014.

FARIA, L.C. et al. Genetic progress during 22 years of black bean improvement. Euphytica, Published Online: 15 May 2014. Disponível em: <http://link.springer.com/article 10.1007\%2Fs10681-014-1135-z>. Acesso em: 11 set. 2014. doi: $10.1007 / \mathrm{s} 10681-014-1135-\mathrm{Z}$.

MATOS, J.W. et al. Trinta e dois anos do programa de melhoramento do feijoeiro comum em Minas Gerais. Ciência e Agrotecnologia, v.31 p.1749-1754, 2007. Disponível em: <http://www.scielo.br/pdf/ cagro/v31n6/a22v31n6.pdf>. Acesso em: 11 set. 2014.

MELO, L.C. et al. Interação com ambientes e estabilidade de genótipos de feijoeiro-comum na Região Centro-Sul do Brasil. Pesquisa Agropecuária Brasileira, v.42, p.715-723, 2007. Disponível em: <http://www.scielo.br/pdf/pab/v42n5/15.pdf> Acesso em: 11 set. 2014.
MOURA, M.M. et al. Potencial de caracteres na avaliação da arquitetura de plantas de feijão. Pesquisa Agropecuária Brasileira, v.48, n.4, p.417-425, 2013. Disponível em: <http:// www.scielo.br/pdf/pab/v48n4/10.pdf>. Acesso em: 11 set. 2014.

OLIVEIRA, G.V. et al. Adaptabilidade e estabilidade de linhagens de feijão comum em Minas Gerais. Pesquisa Agropecuária Brasileira, v.41, p.257-265, 2006. Disponível em: <http://www. scielo.br/pdf/pab/v41n2/a10v41n2.pdf>. Acesso em: 11 set. 2014.

PEREIRA, H.S. et al. Comparação de métodos de análise de adaptabilidade e estabilidade fenotípica em feijoeiro comum. Pesquisa Agropecuária Brasileira, v.44, p.374-383, 2009. Disponível em: <http://www.scielo.br/pdf/pab/v44n4/a07v44n4. pdf $>$. Acesso em: 11 set. 2014.

PIMENTEL-GOMES, F. Curso de estatística experimental. 13.ed. Piracicaba: Nobel, 1990. 468p.

POLIZEL, A.C. et al. Adaptabilidade e estabilidade fenotípica de genótipos de Soja no estado do Mato Grosso. Bioscience Journal, v.29, n.4, p.910-920, 2013. Disponível em: $<$ http://www.seer.ufu. br/index.php/biosciencejournal/article/viewFile/15079/12905>. Acesso em: 11 set. 2014

RAMALHO, M.A.P. et al. Contributions of plant breeding in Brazil - progress and perspectives. Crop Breeding and Applied Biotechnology, n.2, p.111-120, 2012. Disponível em: <http:// www.scielo.br/pdf/cbab/v12nspe/v12nspea12.pdf $>$. Acesso em: 11 set. 2014

RIBEIRO, N.D. et al. Adaptação e estabilidade de produção de cultivares e linhagens-elite de feijão no Estado do Rio Grande do Sul. Ciência Rural, v.38, n.9, p.2434-2440, 2008. Disponível em: <http://www.scielo.br/pdf/cr/v38n9/a18cr179.pdf>. Acesso em: 11 set. 2014.

SCOTT, A.J.; KNOTT, M.A. A cluster analysis method for grouping means in the analysis of variance. Biometric, v.30, p.507-512, 1974. Disponível em: <http://www.ime.usp.br/ abe/ lista/pdfXz71qDk Dx1.pdf>. Acesso em: 10 set. 2014.

SILVA, G.A.P. et al. Análise da adaptabilidade e estabilidade de produção em ensaios regionais de feijoeiro para o Estado de São Paulo. Revista Ceres, v.60, p.59-65, 2013. Disponível em: $<$ http://www.scielo.br/pdf/rceres/v60n1/09.pdf $>$. Acesso em: 11 set. 2014.

VIEIRA, C. et al. Melhoramento do feijão. In: BORÉM, A. Melhoramento de espécies cultivadas. 2.ed. Viçosa: UFV, 2005. p.301-391. 